\title{
Mental health needs targeted federal funds
}

A province-by-province approach to mental health results in piecemeal coverage with large gaps, long wait times and the ongoing criminalization of people with mental illness, say advocates. These are among the reasons why they want mental health to be addressed on a national basis, with federal government leadership. During this election campaign, they're lobbying for increased funding, innovation and better access to treatments and housing.

Canadians, apparently, are not happy with the status quo. For example, 91\% of respondents to a recent poll by the Mood Disorders Society of Canada (MDSC), a not-for-profit charity, said that increasing access to mental health care professionals is a top priority. The poll, conducted in June, garnered 2245 responses, $63 \%$ of whom were not satisfied with their experience of mental health care. Of those, $64 \%$ identified excessive wait times as a problem and $39 \%$ felt that mental illness was not a priority in the health system.

Dave Gallson, MDSC national executive director, says improving mental health care in Canada "can't be done without federal involvement as not only an initiator of increased support but also as a coordinator between the provinces and the territories."

"While mental illnesses constitutes more than $15 \%$ of the disease burden in Canada, the total health funding allocated to mental health care is 7\%," Gallson says. MDSC is advocating for the federal government to increase funding to address mental health issues, such as depression, posttraumatic stress disorder (PTSD) and bipolar disorder.

As of mid-September, the call for reform and a national vision issued by the Centre for Addiction and Mental Health $(\mathrm{CAMH})$ and others had been largely ignored by the political parties in advance of the Oct. 19 election. CAMH President and CEO, Dr. Catherine Zahn says, "I think the health issue of our time is mental health so it's par-

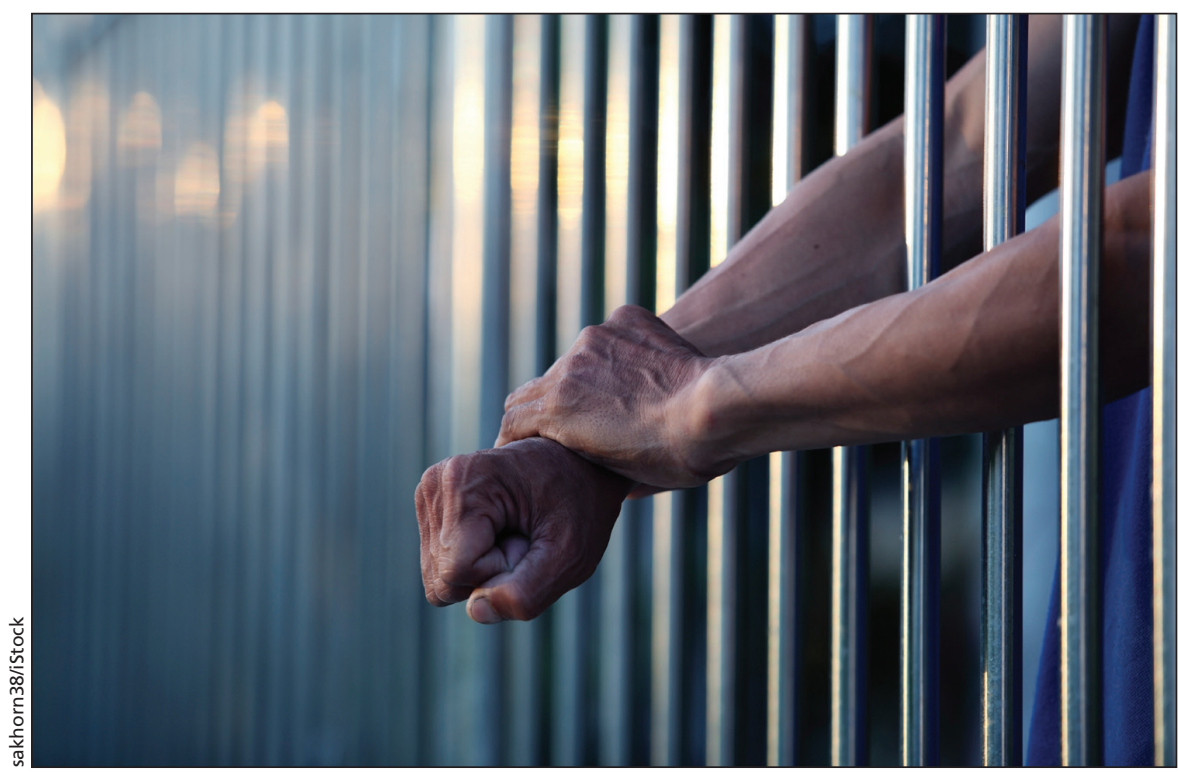

More than $35 \%$ of federal offenders meet the criteria for two or more mental health disorders.

ticularly poignant for me that it's not there."

CAMH wants a "visionary investment" from the federal government, with built-in provincial accountability, to avoid "simply dumping money." The plan should include investment to improve wait times, create better access for rural communities by using practices such as tele-psychiatry and increasing access to evidence-based therapies, such as cognitive behavioural therapy.

Providing better access will help decriminalize mental illness, Zahn says. With proper access to care, "the crisis that people with mental illness get into could be averted and the problematic behaviour, the anxiety, the apparent aggressive or violent behaviour could be averted."

CAMH is also calling for the creation of a national housing strategy and income support for people with mental illness. There are as many as 520000 people in Canada living with mental illness who are vulnerably housed or homeless.

\section{Targeted funding}

At least two influential groups are lobbying for a 5- to 10-year mental health innovation. The Canadian Psychiatric Association (CPA) wants federal government funding to the tune of $\$ 50$ $\$ 100$ million, with the aim of increasing the spread of innovations, and improving the delivery of mental health programs and services within communities.

Currently, "If there's successful programs in various provinces, other areas won't hear about it, says CPA President, Dr. Padraic Carr.

The Canadian Mental Health Association (CMHA) is also backing an innovation fund to increase the federal funding for mental health care within the provinces. "There is a lot of compelling evidence that shows there hasn't been a sufficient investment in mental health," says the Executive Director of CMHA's Toronto branch Steve Lurie. He cites data from the 2013 Mental Health Commission of Canada report, Making the Case for Investing in Mental Health in Canada that forecasts an indirect effect on the economy of $\$ 2.5$ trillion over the next 30 years if the government doesn't spend more on mental health.

Investing in mental health will improve productivity, advocates contend. 
"In any given week 500000 Canadians will not go to work due to mental illness," Carr says. The Mental Health Commission estimates that about $70 \%$ of disability costs are attributed to mental illness and that $\$ 50$ billion is lost each year from the Canadian economy due to mental illnesses. This is why the CPA is also lobbying for a national workplace standard for psychological health and safety.

\section{Suicide prevention}

A national youth suicide prevention plan is a key concern for Partners for Mental Health, a charitable organization founded by Senator Michael Kirby. It is asking for $\$ 100$ million over five years to conduct research, says President Jeff Moat.

"The rate among First Nations youth between 10 and20 years has been four times the overall suicide rate for Canada's young people and that's absolutely deplorable," Moat says. "I would really like to call on all parties to make the commitment to funding suicide prevention during this campaign."

In 2012, the Mental Health Commission of Canada reported that Aboriginal youth commit suicide five to six times more often than nonAboriginal youth and suicide rates for Inuit are 11 times the national average - one of the highest rates in the world.

\section{Under the federal watch}

As Canada's fifth largest provider of health services to groups including federal offenders, First Nation's communities, refugees and the military, the federal government has plenty of hands-on experience providing mental health ser- vices. But its execution leaves something to be desired.

The Correctional Investigator of Canada, Howard Sapers, reports that more than $35 \%$ of offenders meet the criteria for two or more mental health disorders. This group of offenders is less likely to get parole and more likely to be released later in their sentences. Another concern is that inmates who are put in segregation are $31 \%$ more likely to have a mental health issue and twice as likely to have a history of attempted suicide.

Sapers also reports that $24 \%$ of federal inmates are of Aboriginal ancestry.

In Sapers' 2013/14 report, he recommended the federal government increase efforts to hire more mental health professionals. At the time, Correctional Service of Canada had 390 psychologists. Staff at the Correctional Service of Canada had reported a lack of financial and human resources for mental health care.

As for the military, more soldiers died from suicide than from the war in Afghanistan. Records from the Department of National Defence show that there were 178 Canadian Forces suicides and 158 were killed in Afghanistan in the same 12-year period.

A 2013 Statistics Canada survey found that about one in six full-time members of the Canadian Forces experience symptoms of at least one of six mental or alcohol disorders. The disorders included PTSD, a major depressive episode, anxiety disorder, panic disorder, alcohol abuse and/or dependence.

In the Auditor General Michael Ferguson's fall report of 2014, he revealed several barriers for veterans in need of health services and benefits. About
$20 \%$ of veterans had to wait more than eight months to be eligible for access to mental health services.

In the 2015 federal budget, the government acknowledged the increasing number of veterans coming forward with complex disabilities giving Veterans Affairs \$193.4 million over five years to improve their services.

The budget also renewed the Mental Health Commission of Canada's mandate for another 10 years. Conservative Party Leader Stephen Harper announced in August that if re-elected, the Conservatives would have the commission focus on finding links between mental health issues and drugs.

If elected, New Democratic Party Leader Thomas Mulcair promises to set up a \$100-million mental health innovation fund for children and youth aimed at wait-time reduction and improved care. Special emphasis would be given to high-risk First Nations, Inuit and Métis populations, Canadians in rural and remote communities and youth transitioning out of foster care.

Liberal Party Leader Justin Trudeau has pledged an affordable housing policy. If elected, his government would spend $\$ 20$ billion over 10 years in "social infrastructure." He said this plan would be a part of the solution to help people with serious mental health issues and addiction by providing stability.

Voters head to the ballet box Oct. 19; until then, advocates have will have to continue to make sure that mental health is an election issue and becomes part of the national debate. - Shannon Lough, CMAJ

CMAJ 2015. DOI:10.1503/cmaj.109-5153 